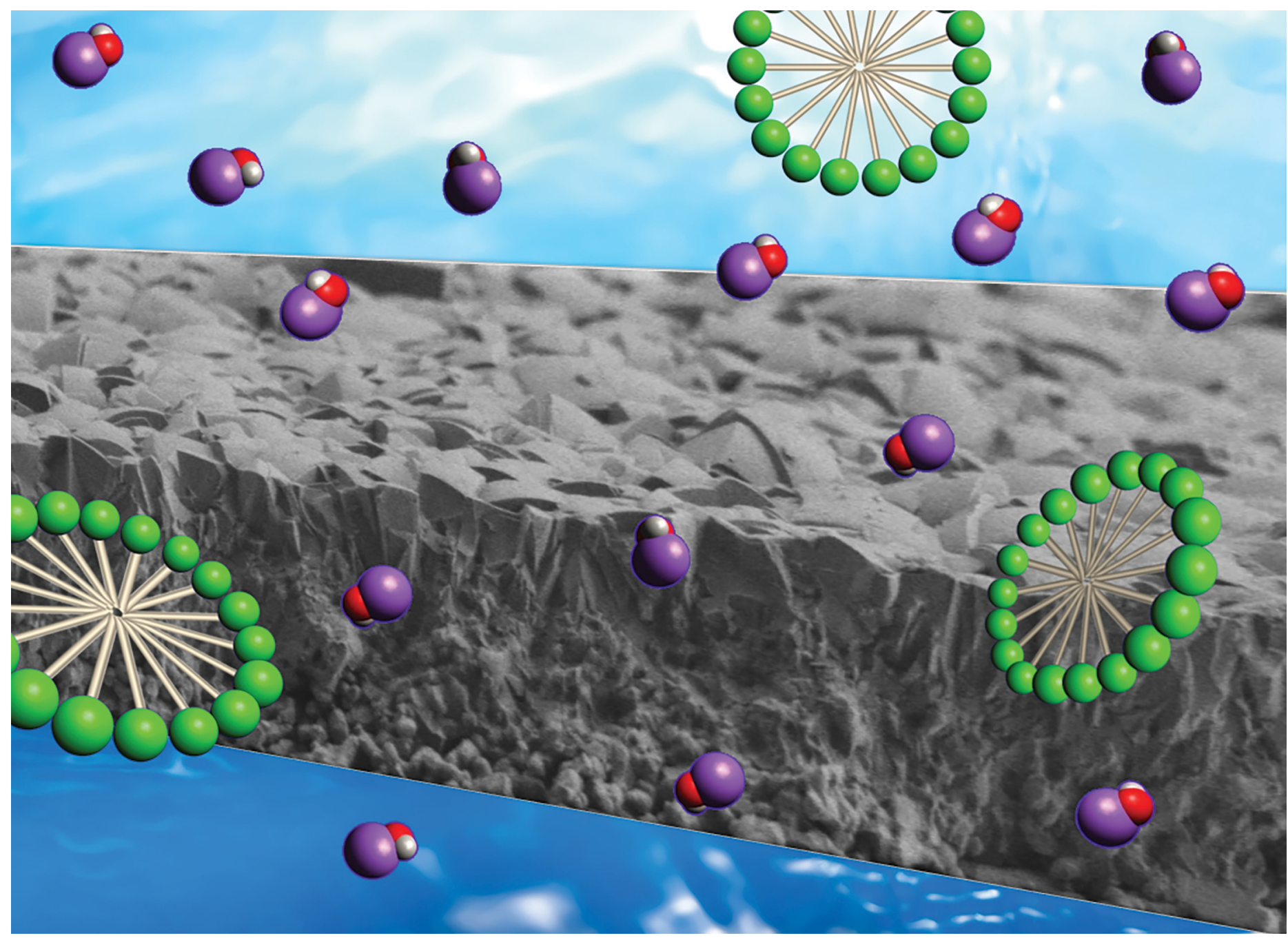

Showcasing research from Professor Matsukata's laboratory, Department of Applied Chemistry, Waseda University, Tokyo, Japan.

Self-defect-healing of silicalite-1 membrane in alkaline aqueous solution with surfactant

Defects in zeolite membranes were rapidly healed by immersion into alkaline aqueous solution in the presence of surfactant. This novel defect-healing technique will contribute to improvement for productivity of zeolite membrane.
As featured in:

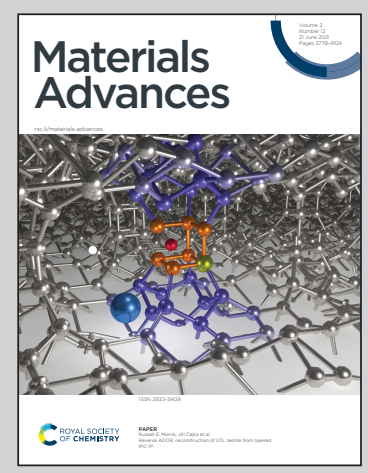

See Motomu Sakai et al., Mater. Adv., 2021, 2, 3892. 
Check for updates

Cite this: Mater. Adv., 2021, 2, 3892

Received 19th April 2021, Accepted 17th May 2021

DOI: $10.1039 / \mathrm{d} 1 \mathrm{ma} 00364 \mathrm{j}$

rsc.li/materials-advances

\title{
Self-defect-healing of silicalite-1 membrane in alkaline aqueous solution with surfactant $\dagger$
}

\author{
Motomu Sakai, (D) *a Hayata Hori ${ }^{b}$ and Masahiko Matsukata (iD c
}

\begin{abstract}
Alkaline treatment with surfactant was applied to silicalite-1 membrane for defect healing. By immersion of silicalite-1 membrane into an aqueous solution of sodium hydroxide and cetyltrimethylammonium bromide (CTAB), defects among crystals were sealed, with amorphous silica leached from the membrane itself. During the treatment, the zeolite pores in the membrane were protected by CTAB from excess alkaline etching. As a result, the separation performance of silicalite-1 membrane was successfully improved by this post-treatment without a decrease in permeability due to the collaborative effect of $\mathrm{NaOH}$ and CTAB. The separation factor for $n$-hexane/2,3-dimethylbutane mixture increased from 86.5 to 559 after only a 15 min treatment. In addition, the separation performances of other zeolite membranes ( $\mathrm{Na}-{ }^{*} \mathrm{BEA}, \mathrm{Na}-\mathrm{ZSM}-5$, and $\mathrm{Na}-\mathrm{MOR}$ ) were also improved by the treatment. This novel defect-healing technique breaks the trade-off line of permeation and separation performance observed with previous post-treatments.
\end{abstract}

\section{Introduction}

Chemical separations require approximately half of all industrial energy and $15 \%$ of the total energy consumed in the US. ${ }^{1}$ In particular, hydrocarbon separations such as olefin/paraffin and xylene isomer separations for basic chemical production consume large amounts of energy. Membrane separation is fervently anticipated as an energy-efficient, economical, $\mathrm{CO}_{2}$-free purification process to reduce the energy consumption in chemical production. Membrane separations have the potential for a 10-fold increase in energy efficiency over thermal processes such as distillation, drying, and evaporation. ${ }^{2}$

Zeolite is one of the most promising membrane materials for hydrocarbon separation because of its high thermal, mechanical, and chemical resistance. Zeolites have uniformly sized micropores defined by their crystal structures. The homogeneous distribution of pore size corresponds to superior sizeexclusion ability called the molecular sieving property. Therefore, zeolite membranes for hydrocarbon isomer separations have been widely studied. $^{3-6}$

Well-prepared zeolite membranes show high separation performances based on their molecular sieving properties.

\footnotetext{
${ }^{a}$ Research Organization for Nano \& Life Innovation, Waseda University, 513 Wasedatsurumaki-cho, Shinjuku-ku, Tokyo 162-0041, Japan. E-mail: saka.moto@aoni.waseda.jp

${ }^{b}$ Department of Applied Chemistry, Waseda University, 513 Wasedatsurumaki-cho, Shinjuku-ku, Tokyo 162-0041, Japan

Advanced Research Institute for Science and Engineering, Waseda University, 513 Wasedatsurumaki-cho, Shinjuku-ku, Tokyo 162-0041, Japan

$\dagger$ Electronic supplementary information (ESI) available. See DOI: 10.1039/d1ma00364j
}

However, inter-crystalline defects such as pinholes and cracks in zeolite membranes often degrade the separation performance. Improvement of productivity could be achieved by a simple posttreatment of the membrane, which could reduce membrane costs. For this reason, some post-treatment methods for inter-crystalline defect healing have been reported..$^{7-11}$

The use of silica deposition techniques has been proposed for defect healing in zeolite membranes. Methods used to deposit amorphous silica include the hydrolysis of silicate or the chemical vapor deposition (CVD) method. ${ }^{7-9}$ In these methods, amorphous silica is formed in membrane defects and seals them, resulting in the improvement of separation performance. However, the chemicals used in these methods, such as tetraethyl orthosilicate (TEOS) and triethoxyfluorosilane (TEFS), are expensive. Moreover, the equipment for CVD treatment would not be cost-effective.

Defect healing in zeolite membranes by carbon deposition has also been reported. The separation performance of ZSM-5 membrane increased by coking of 1,3,5-triisopropylbenzene immersed in membrane defects. ${ }^{10}$ Hong et al. reported a method for blocking defects using water-soluble dye molecules. ${ }^{11}$ The molecular size of the dye was approximately $1 \mathrm{~nm}$, which was too large to diffuse into the zeolitic pores but was sufficient to selectively block microdefects.

Although the methods described above successfully improved separation performance, there was considerably less permeation due to plugging of the zeolite pores by deposited silica, cokes, and dyes. Then, the challenge remains to develop a simple defect-healing technique that does not result in a decrease in permeability. 
Alkaline treatments have been studied for decades as a method to modify zeolite catalysts. ${ }^{12-16}$ The mesopores created by traditional alkaline treatments ease the limitation of diffusion in micropores, and then, catalytic properties improve. ${ }^{12,13}$ Recently, novel alkaline treatment methods with surfactants or pore-filling agents under relatively mild conditions have been developed. ${ }^{14-16}$ Such treatments led to the improvement of not only catalytic properties but also crystallinity and thermal resistance.

We consider that alkaline treatment with surfactant under mild conditions has the potential to heal defects in zeolite membranes. In this study, alkaline treatment with surfactant using sodium hydroxide and cetyltrimethylammonium bromide (CTAB) was carried out for a membrane of silicalite-1, a silicious MFI-type zeolite, to improve separation performance for the first time. The effects of alkaline treatment on crystallinity, defect amounts, and permselectivity were investigated.

\section{Experimental}

\section{Membrane preparation}

Silicalite- 1 membrane was prepared by a secondary growth method according to our previous report. ${ }^{17}$ Silicalite-1 seed crystals were loaded on the outer surface of an $\alpha$-alumina support (o.d. $=10 \mathrm{~mm}$, i.d. $=7 \mathrm{~mm}$, length $=30 \mathrm{~mm}$, average pore size $=150 \mathrm{~nm}$, Noritake Co. Ltd) by a dip-coating technique. Synthesis solution was prepared by mixing distilled water, tetrapropylammonium hydroxide (TPAOH, 1.0 $\mathrm{M}$ in $\mathrm{H}_{2} \mathrm{O}$, SigmaAldrich), ethanol ( $>99.5 \%$ (GC), Kanto Chemical) and tetraethyl orthosilicate (>99.0\% (GC), Sigma-Aldrich).

The molar composition of the synthesis solution was adjusted to $25 \mathrm{SiO}_{2}: 3 \mathrm{TPAOH}: 1650 \mathrm{H}_{2} \mathrm{O}: 200 \mathrm{EtOH}$. Hydrothermal crystallization was conducted at $373 \mathrm{~K}$ for 7 days. After crystallization, the membranes were washed with boiling water and dried at $383 \mathrm{~K}$ for $12 \mathrm{~h}$. The dried silicalite- 1 membrane was calcined at $773 \mathrm{~K}$ for $8 \mathrm{~h}$ to remove TPA cation occluded in the zeolite framework prior to use.

\section{Alkaline treatment with surfactant}

Alkaline treatment of the silicalite-1 membrane was performed with aqueous solution of $0.1 \mathrm{M} \mathrm{NaOH}$ (>97.0\%, Kanto Chemical) and $0.05 \mathrm{M}$ cetyltrimethylammonium bromide (CTAB, MP Biomedicals). Next, $0.320 \mathrm{~g}$ of $\mathrm{NaOH}$ and $1.458 \mathrm{~g}$ of CTAB were dissolved in $80 \mathrm{~g}$ of distilled water in a Teflon beaker. The aqueous solution was pre-heated to $353 \mathrm{~K}$ while stirring for $30 \mathrm{~min}$. Silicalite-1 membrane was immersed in the aqueous solution at $353 \mathrm{~K}$, and the solution was stirred for a given period. After that, the silicalite-1 membrane was washed with boiling water to remove the aqueous solution, and then dried at $383 \mathrm{~K}$ overnight. The dried silicalite- 1 membrane was calcined in a furnace under atmospheric pressure at $673 \mathrm{~K}$ for $3 \mathrm{~h}$ with a heating rate of $3 \mathrm{~K} \mathrm{~min}^{-1}$.

Separation tests and characterizations were carried out after calcination. The sequence of separation test, XRD measurement, nano-permporometry, $\mathrm{N}_{2}$ adsorption, and alkaline treatment was repeated for the same membrane. The accumulated alkaline treatment periods were fixed for $5,15,30,45$, and $70 \mathrm{~min}$.

\section{Permeation and separation tests}

The permeation and separation tests for the silicalite- 1 membrane were carried out in vapor permeation mode. The vaporized equimolar mixture of $n$-hexane and 2,3-dimethylbutane was fed to the outer surface of the silicalite- 1 membrane. The membrane temperature was maintained at 373, 423, 473, and $573 \mathrm{~K}$. The permeable side was swept with Ar gas. Both the feed and permeable sides were maintained at atmospheric pressure.

The permeate was analyzed by gas chromatography (GC-8A, Shimadzu). Flux $\left(J_{\mathrm{X}}\right)$ and permeance $\left(P_{\mathrm{X}}\right)$ were calculated using the following equations.

$$
\begin{gathered}
J_{\mathrm{X}}\left(\mathrm{mol} \mathrm{m}^{-2} \mathrm{~s}^{-1}\right)=u_{\mathrm{X}} A^{-1} \\
\Pi_{\mathrm{X}}\left(\mathrm{mol} \mathrm{m}^{-2} \mathrm{~s}^{-1} \mathrm{~Pa}^{-1}\right)=J_{\mathrm{X}} \Delta P_{X}^{-1}
\end{gathered}
$$

where $u_{\mathrm{X}}$ denotes the flow rate $\left(\mathrm{mol} \mathrm{s}^{-1}\right)$ of component $\mathrm{X}$, $A$ denotes the membrane area $\left(\mathrm{m}^{2}\right)$, and $\Delta P_{\mathrm{X}}$ denotes the partial pressure difference of $\mathrm{X}$ between the feed and permeable sides (Pa). The separation factor, $\alpha$, was calculated as the following equation,

$$
\alpha_{\mathrm{A} / \mathrm{B}}(-)=\left(Y_{\mathrm{A}} / Y_{\mathrm{B}}\right) /\left(X_{\mathrm{A}} / X_{\mathrm{B}}\right)
$$

where $Y_{\mathrm{A}}$ and $Y_{\mathrm{B}}$ represent mol fractions of components A and B in the permeable side, respectively. $X_{\mathrm{A}}$ and $X_{\mathrm{B}}$ represent mol fractions of components $\mathrm{A}$ and $\mathrm{B}$ in the feed side, respectively.

\section{Membrane characterizations}

A nano-permporometry test was performed using a Porometer Nano-6 (MicrotracBEL Corp.). Condensable vapor and inert gas were supplied to the membrane. The flow rate of inert gas in the permeable side was measured during the test. Because the pores in the membrane were filled by the condensation of vapor, the flow rate of inert gas decreased with increasing relative pressure of vapor. The relationship between the relative pressure of condensable vapor and the flow rate of inert gas represents the pore size distribution. Pretreatment was performed at $573 \mathrm{~K}$ for $3 \mathrm{~h}$ to remove adsorbed molecules on the membrane. In this study, Ar gas and $n$-hexane were used as the inert gas and condensable vapor, respectively. The measurement was taken at $333 \mathrm{~K}$ with the relative vapor pressure in the range of $0-0.3$.

The micropore volume in the silicalite- 1 membrane was evaluated by $\mathrm{N}_{2}$ adsorption measurement. The measurement was performed non-destructively using BELSORP-max (MicrotracBEL Corp.). Pretreatment was performed at $573 \mathrm{~K}$ for $8 \mathrm{~h}$ under vacuum before the adsorption test. Adsorption measurements were carried out at $77 \mathrm{~K}$.

\section{Results and discussion}

The $n$-hexane( $n$-Hex)/2,3-dimethylbutane(2,3-DMB) separation test was performed to investigate the effect of alkaline treatment on the permselectivity of the silicalite- 1 membrane. The pore size 
of silicalite- 1 was approximately $0.55 \mathrm{~nm}$, and the molecular diameters of $n$-Hex and 2,3-DMB were approximately $0.435 \mathrm{~nm}$ and $0.58 \mathrm{~nm}$, respectively. ${ }^{18}$ Therefore, if the silicalite-1 membrane had no defect, only $n$-Hex would penetrate through the micropores of the membrane because of the molecular sieving effect. In other words, the permeation of 2,3-DMB indicated the presence of defects that resulted in non-zeolitic pathways through the silicalite- 1 membrane.

Fig. 1 shows the permeation and separation performance of a silicalite- 1 membrane at $573 \mathrm{~K}$ as a function of the treatment period. When the alkaline treatment was carried out for $5 \mathrm{~min}$, the 2,3-DMB permeance decreased from $4.52 \times 10^{-10}$ to $1.29 \times$ $10^{-10} \mathrm{~mol} \mathrm{~m}^{-2} \mathrm{~s}^{-1} \mathrm{~Pa}^{-1}$, and the separation factor remarkably increased from 86.5 to 334 . After further alkaline treatment for the total treatment period of $15 \mathrm{~min}$, the 2,3-DMB permeance further decreased to $1.13 \times 10^{-10} \mathrm{~mol} \mathrm{~m}^{-2} \mathrm{~s}^{-1} \mathrm{~Pa}^{-1}$, resulting in the separation factor increasing up to 559 .

The decrease in 2,3-DMB permeance by the alkaline treatment suggests the decrease of the non-zeolitic pathway through which 2,3-DMB is able to permeate. However, a slight increase in $n$-Hex permeance indicated that the micropores did not collapse after the alkaline treatment. Therefore, we considered that the non-zeolitic pathway in the silicalite- 1 membrane was blocked by the alkaline treatment with CTAB while maintaining its micropores. In the following section, we discuss the reason why the membrane retained high permeation performance after the alkaline treatment.

When the alkaline treatment was performed up to $30 \mathrm{~min}$, the 2,3-DMB permeance tended to increase. After a $70 \mathrm{~min}$ treatment, the 2,3-DMB permeance drastically increased to $2.38 \times 10^{-8} \mathrm{~mol} \mathrm{~m}^{-2} \mathrm{~s}^{-1} \mathrm{~Pa}^{-1}$, resulting in a decrease in the separation factor at $573 \mathrm{~K}$ to 3.13 . The increase in 2,3-DMB permeance resulting from the longer periods of alkaline treatment would be caused by the creation of large non-zeolitic pathways through which 2,3-DMB penetrated by excess alkaline etching.

To confirm the reproducibility of this method, alkaline treatments were performed on four other silicalite- 1 membranes using the same method. In all cases, 2,3-DMB permeances decreased and the separation factors increased in all membranes

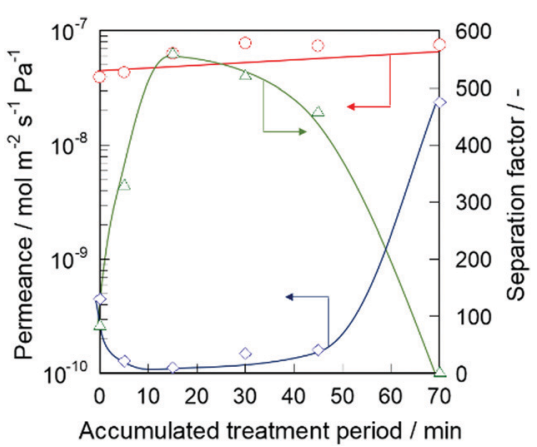

Fig. 1 Permeation and separation performance at $573 \mathrm{~K}$ of silicalite-1 membrane as a function of treatment period: $\bigcirc, n$-hexane; $\diamond, 2,3-$ dimethylbutane; $\triangle$, separation factor.

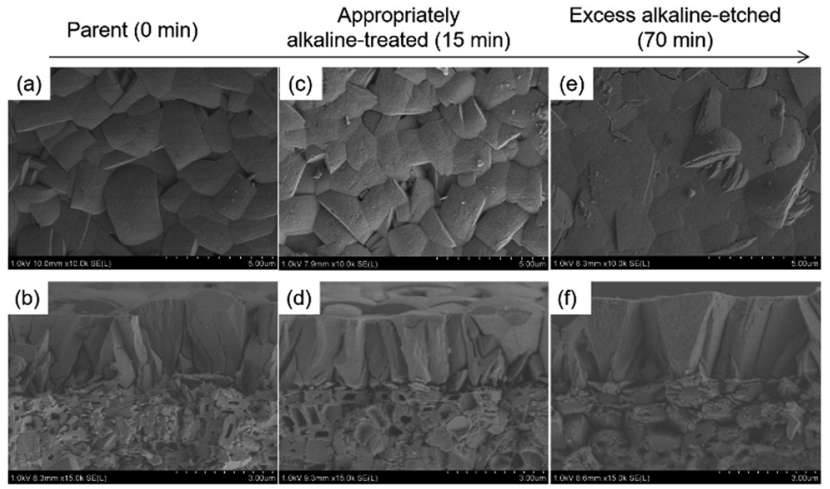

Fig. 2 FE-SEM images of alkaline-treated silicalite-1 membranes at each accumulated treatment period. (a), (c), and (e) membrane surfaces; (b), (d), and (f) cross-sections

tested (as shown in Table ES1 in the ESI $\dagger$ ), and we successfully affirmed the reproducibility. In addition, the treatment was carried out for other types of zeolite membranes (Na-*BEA, Na-ZSM-5, and Na-MOR), and then, the separation performances of these membranes increased as well (shown as Table ES2 in the ESI $\dagger$ ).

Fig. 2 shows typical FE-SEM images of alkaline-treated silicalite-1 membranes during each treatment period. When the alkaline treatment was performed for $15 \mathrm{~min}$, partial dissolution of seed crystals occurred, as shown in Fig. 2(d) (the dissolved part is represented by a blue arrow in the enlarged images shown in the ESI $\dagger$ as ES3). However, no significant change could be observed from the top view of the effective separation layer in the vicinity of the membrane surface, as shown in Fig. 2(c). After a 70 min treatment, crystals of the seed layer were severely collapsed by excess alkaline etching, and then large voids were visible among the seed crystals (Fig. 2(f)). In addition, the dissolution on the membrane surface was observed after the 70 min treatment, as shown in Fig. 2(e). The changes in the morphological features of the membrane after the 70 min treatment agreed with the results of the separation test.

A nano-permporometry test was performed to evaluate the changes in the non-zeolitic pathway during the alkaline treatment. Fig. 3 shows the ratio of the non-zeolitic pathway and separation factor of a treated silicalite- 1 membrane. The ratio of the non-zeolitic pathway was obtained by dividing argon permeance at $p p_{\mathrm{s}}{ }^{-1}$ of 0.2 by the permeance at $p p_{\mathrm{s}}{ }^{-1}$ of 0 according to the method, which was proposed by Hedlund and his co-workers. ${ }^{7,19}$

When the alkaline treatment was performed for $5 \mathrm{~min}$, the ratio of the non-zeolitic pathway decreased from $4.31 \times 10^{-3}$ to $1.97 \times 10^{-3}$, and the separation factor increased from 86.5 to 332, as shown in Fig. 1. Furthermore, after the $15 \mathrm{~min}$ alkaline treatment, the ratio of the non-zeolitic pathway decreased and the separation factor increased as well. The non-zeolitic pathway in the silicalite- 1 membrane was clearly healed in the early stage of alkaline treatment. When the alkaline treatment was prolonged up to $70 \mathrm{~min}$, the ratio of the non-zeolitic pathway 


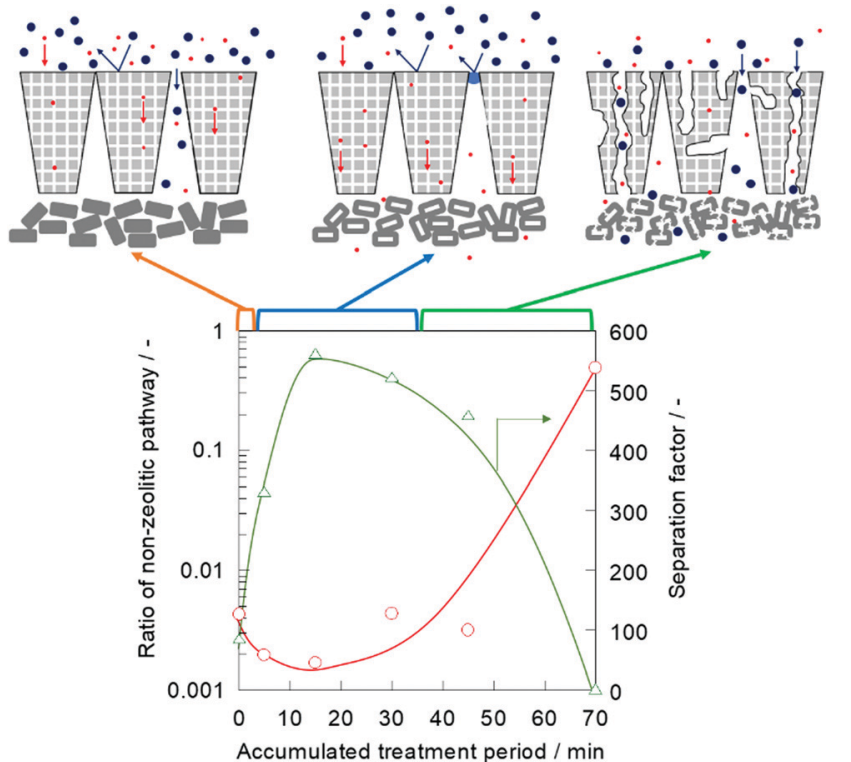

Fig. 3 Relationship between the ratio of non-zeolitic pathway and separation factor (573 K).

remarkably increased to $4.91 \times 10^{-1}$, and the separation factor decreased to 3.13. This result indicated that the molecular sieving effect was obstructed because of the large number of non-zeolitic pathways formed by excess alkaline etching for a 70 min treatment.

The X-ray diffraction (XRD) measurement was performed to evaluate the changes in the crystallinity of the silicalite-1 membrane over the course of the alkaline treatment. Fig. 4 shows the XRD patterns of the silicalite- 1 membrane during different treatment periods. No obvious reflection peaks other

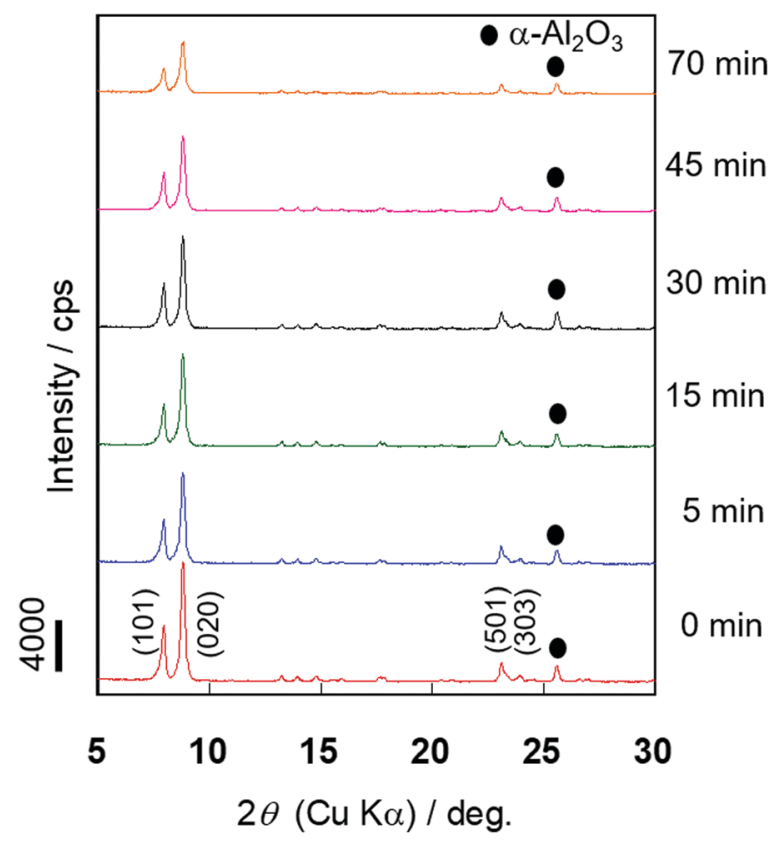

Fig. 4 XRD patterns of silicalite-1 membranes with different accumulated treatment periods. than those corresponding to the MFI-type zeolite and support, $\alpha$-alumina, were observed for all samples. There was little change in the intensities of the diffraction peaks assigned to the MFI-type zeolite until 30 min of alkaline treatment elapsed, suggesting that the crystal structure of MFI was maintained in the early stage of alkaline treatment. When the alkaline treatment was performed for $>45 \mathrm{~min}$, the intensities of the diffraction peaks decreased, suggesting that the crystal structure collapsed due to the progression of desilication.

Micropore volume, an index of crystallinity of zeolite, was evaluated by $\mathrm{N}_{2}$ adsorption measurements to quantitatively determine the crystallinity change before and after the alkaline treatment. The volume of the micropores in the silicalite- 1 membrane was obtained by the Saito-Foley (S-F) method. ${ }^{20,21}$ The adsorption amount of $\mathrm{N}_{2}$ at $p p_{\mathrm{s}}{ }^{-1}$ was $1.0 \times 10^{-4}$, and this number was adopted as the saturated adsorption amount in zeolite pores because this quantity represents the adsorbed amount required for the saturation of a cylindrical pore with a diameter of $0.55 \mathrm{~nm}$, which is a size comparable to the MFI-type zeolite pore. In addition, we defined crystallinity as the ratio of micropore volume before and after the treatment.

Table 1 lists the accumulated treatment period and micropore volume. The micropore volume increased during the early stage of alkaline treatment for $15 \mathrm{~min}$, and then, no significant change in micropore volume was observed after $45 \mathrm{~min}$ of prolonged alkaline treatment. The crystallinity decreased after the 70 min treatment, suggesting that the zeolite structure collapsed by excess alkaline etching.

The improvement in crystallinity by the alkaline treatment for zeolite powder has previously been reported in several studies. $^{12,22,23}$ These studies suggested that this phenomenon occurred because areas of poor crystallinity in zeolite were preferentially dissolved by the alkaline treatment, resulting in an overall higher crystallinity. We also considered that amorphous or low crystallinity parts in the silicalite-1 membrane were preferentially dissolved in the early stage of our alkaline treatment, and then, the micropore volume increased. The micropore volume should decrease after the treatment if alkalinity and surfactant remain in the micropore. This result also suggests that alkalinity and surfactant were successfully removed by washing and calcination after healing.

To study the roles of both $\mathrm{NaOH}$ and CTAB, treatments with only $\mathrm{NaOH}$ or CTAB aqueous solution were carried out, respectively. Table 2 lists the permeation and separation properties for each treatment.

\begin{tabular}{lll} 
Table 1 Accumulated treatment period and micropore volumes \\
\hline $\begin{array}{l}\text { Accumulated treatment } \\
\text { period/min }\end{array}$ & $\begin{array}{l}\text { Micropore volume/ } \\
10^{-3} \mathrm{~cm}^{3} \mathrm{~g}^{-1}\end{array}$ & Crystallinity/\% \\
\hline 0 & 9.20 & 100 \\
15 & 9.84 & 107 \\
30 & 9.97 & 108 \\
45 & 9.86 & 107 \\
70 & 8.62 & 94
\end{tabular}


Table 2 Separation and permeation properties of membranes with $\mathrm{NaOH}$ or CTAB

\begin{tabular}{|c|c|c|c|}
\hline \multirow[t]{2}{*}{ Membranes } & \multicolumn{2}{|c|}{$\begin{array}{l}\text { Permeance } / 10^{-8} \\
\mathrm{~mol} \mathrm{~m}^{-2} \mathrm{~s}^{-1} \mathrm{~Pa}^{-1}\end{array}$} & \multirow{2}{*}{$\begin{array}{l}\text { Separatior } \\
\text { factor/- }\end{array}$} \\
\hline & $n$-Hex & 2,3-DMB & \\
\hline M1 parent & 4.84 & 0.235 & 20.6 \\
\hline M1 with $\mathrm{NaOH}$ & 5.31 & 1.36 & 3.90 \\
\hline M2 parent & 4.99 & 0.0687 & 72.6 \\
\hline M2 with CTAB & 5.72 & 0.0721 & 79.3 \\
\hline
\end{tabular}

The 2,3-DMB permeance of the silicalite- 1 membrane treated with $\mathrm{NaOH}(\mathrm{aq})$ increased from $2.35 \times 10^{-9}$ to $1.36 \times$ $10^{-8} \mathrm{~mol} \mathrm{~m}^{-2} \mathrm{~s}^{-1} \mathrm{~Pa}^{-1}$, and the separation factor decreased from 20.6 to 3.90 after only a 15 min treatment, indicating that without $\mathrm{CTAB}, \mathrm{NaOH}$ treatment could easily result in the formation of a non-zeolitic pathway. In contrast, the permeation of 2,3-DMB into the silicalite- 1 membrane treated with CTAB did not significantly change, and the separation factor also hardly changed. It was suggested that defects on the silicalite-1 membrane were not healed by CTAB molecules or cokes derived from CTAB calcination.

These results clearly showed that the combination of $\mathrm{NaOH}$ and CTAB was essential for the improvement of separation performance. $\mathrm{CTAB}$ has an important role as protector for the micropores of the silicalite- 1 membrane during the alkaline treatment. We considered two hypotheses regarding the role of CTAB in our alkaline treatment. One of them is that CTAB protects micropores in a membrane by adsorbing on the external surface during alkaline treatment. Hui et al. reported that CTAB was adsorbed on the external surface of zeolite to protect the zeolite structure via multilayer adsorption during their alkaline treatment. ${ }^{14}$ The other is that CTAB protects micropores by filling them. Iyoki et al. reported that treatment with a pore-filling hydroxide such as TEAOH and fluoride species resulted in ${ }^{*}$ BEA-, MFI-, and MOR-type zeolite with high stability against high-temperature steaming by reducing the number of defect sites. ${ }^{15}$ They noted that TEA cations worked as a pore filler to stabilize the framework during the treatment. Wang et al. reported that after alkaline treatment of ZSM-22, the templates were retained in the micropores. ${ }^{24}$ The existence of retained templates in micropores increased the preservation of the zeolite crystal by hindering the contact between the desilication agent and $\mathrm{Si}-\mathrm{O}-\mathrm{Si}$ linkages.

We can conclude that the separation performance of the silicalite-1 membrane can be improved by this alkaline treatment possibly because non-zeolitic pathways between crystals are healed by amorphous silica leached from seed crystals and the low crystallinity parts. In other words, self-defect-healing occurred in the membrane by the use of a silica source derived from itself. Additionally, CTAB protects the micropores in a membrane while defect healing occurs.

Finally, we compared the effect of our alkaline treatment with other previously reported post-treatments for defect healing. Herein, the relative permeance and relative separation factor are defined as follows. The relative permeance is a ratio of permeance

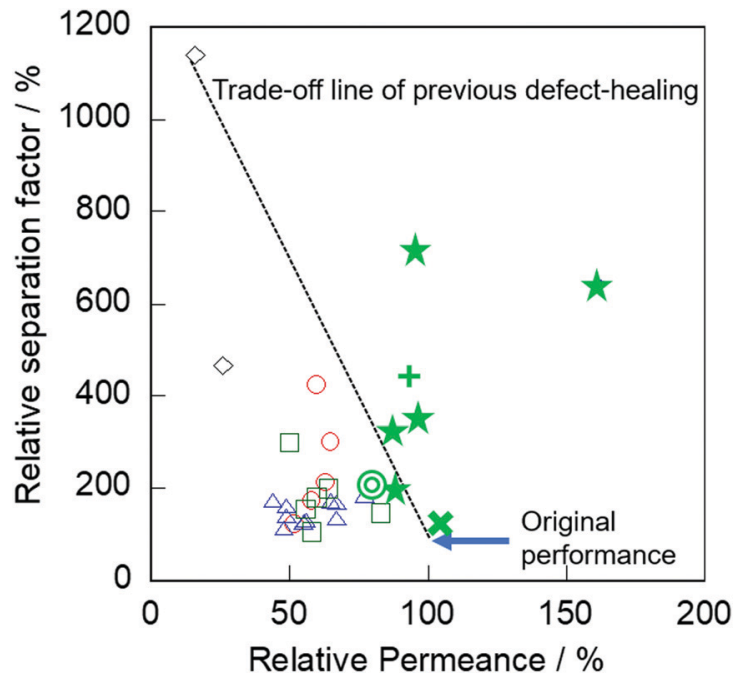

Fig. 5 Relative separation factor as a function of relative permeance in

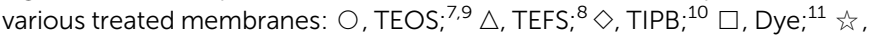
AT with CTAB (this study) for slilicalite-1; +, for Na-BEA membrane; ๑ , for Na-MOR membrane; $\times$, for Na-ZSM-5 membranes.

obtained through the treated membrane and parent membrane: the relative separation factor is the ratio of the separation factor obtained through the parent and treated membranes as well. Fig. 5 shows the relative separation factor as a function of relative permeance in various treated membranes.

In previous post-treatments for defect healing, ${ }^{7-11}$ significant degradation of permeation performance occurred by obstruction of micropores, as described in the Introduction. In contrast, our membranes exhibited no severe decrease in permeance by the alkaline treatment compared with the posttreatment methods previously reported. Specifically, the relative permeances after the alkaline treatment with surfactant were $88-160 \%$ with relative separation factors of $200-711 \%$.

\section{Conclusions}

Separation performance was successfully increased by rapid alkaline treatment, and there was no decrease in permeability. The ratio of the non-zeolitic pathway in silicalite- 1 membrane decreased, and the separation performance was improved by the use of both $\mathrm{NaOH}$ and CTAB. CTAB has an important role as a protector of micropores in the silicalite- 1 membrane during alkaline treatment. The effectiveness of the treatment for other types of zeolite membranes (Na-*BEA, Na-ZSM-5, and Na-MOR) was also confirmed. This simple alkaline treatment with surfactant is a promising technique that can be used for defect healing of molecular sieving zeolite membranes.

\section{Author contributions}

M. Sakai designed the study and wrote the initial draft of the manuscript. H. Hori contributed to data collection and interpretation. All authors have approved the final version of the manuscript. 


\section{Conflicts of interest}

There are no conflicts to declare.

\section{Acknowledgements}

Part of this paper is based on results obtained from a project, JPNP14002, commissioned by the New Energy and Industrial Technology Development Organization (NEDO).

\section{References}

1 D. S. Sholl and R. P. Lively, Nature, 2016, 532, 435.

2 K. A. Thompson, R. Mathias, D. Kim, J. Kim, N. Rangnekar, J. R. Johnson, S. J. Hoy, I. Bechis, A. Tarzia, K. E. Jelfs, B. A. McCool, A. G. Livingston, R. P. Lively and M. G. Finn, Science, 2020, 369, 310.

3 M. Y. Jeon, D. Kim, P. Kumar, P. S. Lee1, N. Rangnekar, P. Bai, M. Shete, B. Elyassi, H. S. Lee, K. Narasimharao, S. N. Basahel, S. Al-Thabaiti, W. Xu, H. J. Cho, E. O. Fetisov, R. Thyagarajan, R. F. DeJaco, W. Fan, K. A. Mkhoyan, J. I. Siepmann and M. Tsapatsis, Nature, 2017, 543, 690.

4 P. Kumar, D. W. Kim, N. Rangnekar, H. Xu, E. O. Fetisov, S. Ghosh, H. Zhang, Q. Xiao, M. Shete, J. I. Siepmann, T. Dumitrica, B. McCool, M. Tsapatsis and K. A. Mkhoyan, Nat. Mater., 2020, 19, 443.

5 D. Kim, M. Y. Jeon, B. L. Stottrup and M. Tsapatsis, Angew. Chem., Int. Ed., 2018, 57, 480.

6 B. Min, S. Yang, A. Korde, Y. H. Kwon, C. W. Jones and S. Nair, Angew. Chem., Int. Ed., 2019, 58, 8201.

7 S. Karimi, D. Korelskiy, L. Yu, J. Mouzon, A. A. Khodadadi, Y. Mortazavi, M. Esmaeili and J. Hedlund, J. Membr. Sci., 2015, 489, 480 .
8 N. Kosinov, V. G. P. Sripathi and E. J. M. Hensen, Microporous Mesoporous Mater., 2014, 194, 24.

9 M. Nomura, T. Yamaguchi and S. Nakao, Ind. Eng. Chem. Res., 1997, 36, 4217.

10 Y. Yan, M. E. Davis and G. R. Gavalas, J. Membr. Sci., 1997, 123, 95. 11 S. Hong, D. Kim, Y. Jeong, E. Kim, J. C. Jung, N. Choi, J. Nam, A. C. K. Yip and J. Choi, Chem. Mater., 2018, 30, 3346.

12 M. Ogura, S. Shinomiya, J. Tateno, Y. Nara, M. Nomura, E. Kikuchi and M. Matsukata, Appl. Catal., A, 2001, 219, 33.

13 M. Ogura, S. Shinomiya, J. Tateno, Y. Nara, E. Kikuchi and M. Matsukata, Chem. Lett., 2000, 882.

14 H. Liu, S. Xie, W. Xin, S. Liu and L. Xu, Catal. Sci. Technol., 2016, 6, 1328.

15 K. Iyoki, K. Kikumasa, T. Onishi, Y. Yonezawa, A. Chokkalingam, Y. Yanaba, T. Matsumoto, R. Osuga, S. P. Elangovan, J. N. Kondo, A. Endo, T. Okubo and T. Wakihara, J. Am. Chem. Soc., 2020, 142, 3931.

16 J. G. Martinez, M. Johnson, J. Valla, K. Lib and J. Y. Ying, Catal. Sci. Technol., 2012, 2, 987.

17 M. Sakai, T. Kaneko, Y. Sasaki, M. Sekigawa and M. Matsukata, Crystals, 2020, 10, 949.

18 O. C. Gobin, S. J. Reitmeier, A. Jentys and J. A. Lercher, J. Phys. Chem. C, 2011, 115, 1171.

19 D. Korelskiy, M. Grahn, J. Mouzon and J. Hedlund, J. Membr. Sci., 2012, 417-418, 183.

20 A. Saito and H. C. Foley, AIChE J., 1991, 37, 429.

21 A. Saito and H. C. Foley, Microporous Mater., 1995, 3, 531.

22 M. Bjørgen, F. Joensen, M. S. Holm, U. Olsbye, K. P. Lillerud and S. Svelle, Appl. Catal., A, 2008, 345, 43.

23 A. Chawla, N. Linares, J. D. Rimer and J. G. Martínez, Chem. Mater., 2019, 31, 5005.

24 X. Wang, X. Zhang and Q. Wang, Ind. Eng. Chem. Res., 2019, 58, 8495. 